\title{
EFEK KECERDASAN EMOSI DAN KEPUASAN KOMUNIKASI TERHADAP ORGANIZATIONAL CITIZENSHIP BEHAVIOR KARYAWAN
}

\author{
Pusparani Ratna Dwisara, Ita Juwitaningrum, Diah Zaleha Wyandini \\ Departemen Psikologi Universitas Pendidikan Indonesia \\ puspadwisara@gmail.com,juwitaningrum_psi@upi.edu,diah.wyandini_psi@upi.edu
}

\begin{abstract}
This study aimed to determine the influence of emotional intelligence and communication satisfaction of organizational citizenship behavior of employees. This research used quantitative approach with correlational methods. The participants of this research was 300 employees in Bandung. The instruments were emotional intelligence (Goleman that modified by Muta'asifah (2013), communication satisfaction (Downs and Hazen, 1977), and organizational citizenship behavior (Kumar and Shah, 2015). The analysis of this research was multiple linier regression analysis. The result of this research showed that there is a effect of emotional intelligence and communication satisfaction on organizational citizenship behavior of employees in Bandung. In order to improve the aspects of this research that are still lacking, it is necessary to conduct training and counseling on employees.
\end{abstract}

Key words: emotional intelligence, communication satisfaction, OCB, employees

\begin{abstract}
Abstrak
Penelitian ini bertujuan untuk mengetahui pengaruh kecerdasan emosi dan kepuasan komunikasi terhadap organizational citizenship behavior pada karyawan BUMN di Kota Bandung. Penelitian ini menggunakan pendekatan kuantitatif dengan metode korelasional. Sampel dalam penelitian ini adalah 300 karyawan yang bekerja di BUMN di Kota Bandung. Instrumen yang digunakan peneliti yaitu instrumen kecerdasan emosi dari Goleman dan dimodifikasi oleh Muta'asifah (2013), instrumen kepuasan komunikasi dari Downs dan Hazen (1977), serta instrumen organizational citizenship behavior dari Podsakoff dan dimodifikasi oleh Kumar dan Shah (2015). Teknik analisis yang digunakan dalam penelitian ini adalah teknik analisis regresi liniear dan regresi berganda. Hasil penelitian ini menunjukkan bahwa terdapat pengaruh yang signifikan antara kecerdasan emosi dan kepuasan komunikasi terhadap organizational citizenship behavior pada karyawan di Kota Bandung.
\end{abstract}

Kata kunci: Kecerdasan emosi, kepuasan komunikasi, OCB, karyawan

\section{PENDAHULUAN}

Saat ini persaingan antar perusahaan menjadi lebih ketat. Dalam menyikapi hal ini, perusahaan harus memiliki strategi agar dapat bersaing dengan perusahaan-perusahaan 
lain. Karyawan merupakan salah satu aspek penting yang ada di suatu perusahaan. Menurut Mayo, karyawan dengan segala pengetahuan, ide, dan inovasi yang dimilikinya merupakan dasar penggerak perusahaan (Ongkorahardjo, Susanto, \& Rachmawati, 2009). Pentingnya peran karyawan ini membuat perusahaan tidak lagi memandang karyawan sebagai sumber daya (resource) untuk mencapai tujuan perusahaan maupun organisasi melainkan karyawan dipandang sebagai aset (capital) untuk menjalankan, mengembangkan, dan mencapai tujuan organisasi maupun perusahaan secara optimal (Kimberly \& Utoyo, 2002).

Berdasarkan penelitian, untuk meningkatkan efektivitas organisasi dibutuhkan karyawan yang tidak hanya bekerja sesuai dengan tugasnya, tetapi juga mampu melakukan hal-hal di luar deskripsi pekerjaan. Hal ini hanya dapat tercapai apabila organisasi dapat mengembangkan Organizational Citizenship Behavior (OCB) (Natalia $\&$ Suyasa, 2008). Pernyataan tersebut sejalan dengan pernyataan Organ yang menyebutkan bahwa karyawan dengan OCB akan melakukan perilaku diluar peran formalnya dalam pekerjaan dengan sukarela (Podsakoff, Mackenzie, \& Moorman, 1990).

OCB adalah kegiatan sukarela dari anggota organisasi yang mendukung fungsi organisasi sehingga perilaku ini lebih bersifat menolong yang dinyatakan dalam tindakan yang menunjukkan sikap tidak mementingkan diri sendiri, melainkan lebih berorientasi pada kesejahteraan orang lain (Kurniawan, 2015). Menurut Fitriastuti (2013), OCB merupakan salah satu faktor yang memberikan sumbangan pada hasil kerja organisasi secara keseluruhan. OCB dianggap menguntungkan organisasi yang tidak bisa ditumbuhkan dengan basis kewajiban peran formal maupun dengan bentuk kontrak atau rekompensasi.

Masalah yang muncul pada karyawan adalah mengenai kehadiran dan penggunaan waktu istirahat yang tidak sesuai dengan aturan. Karyawan masih ada yang terlambat masuk ke kantor. Beberapa karyawan masih ada yang menggunakan jam kerjanya untuk beristirahat lebih awal dan kembali bekerja setelah jam istirahat habis. Dalam hal mengikuti kegiatan perusahaan, tak jarang karyawan menghadiri kegiatan tersebut karena ditunjuk oleh atasan, bukan karena kemauan diri sendiri. Dari pernyataanpernyataan tersebut maka dapat dikatakan masih ada aspek-aspek OCB yang harus ditingkatkan dan diperbaiki oleh perusahaan agar perusahaan dapat mencapai tujuannya.

OCB dapat timbul dari berbagai faktor, di antaranya karena pengaruh faktor dari dalam diri individu dan dari luar diri individu (Sumiyarsih W, Mujiasih E, Ariati, 2012). Faktor dari dalam diri individu yang berpengaruh terhadap OCB antara lain kepribadian (Sumiyarsih W, Mujiasih E, Ariati, 2012), suasana hati (Glomb, Bhave, Miner, \& Wall, 2011), dan kecerdasan emosi (Sahafi, Danaee, Sarlak, \& Haghollah, 2012; Sahafi, Danaee, Sariak \& Haghollahi, 2012). 
Kemampuan individu dalam mengelola emosi baik emosi yang muncul dari dirinya sendiri maupun dari orang lain disebut kecerdasan emosi (Masruroh, 2014). Menurut penelitian, emosi atau suasana hati yang baik dapat membuat seseorang memandang orang lain atau peristiwa dengan cara yang lebih positif sehingga akan membuat orang merasa lebih optimis mengenai kemampuannya untuk mencapai tujuan, meningkatkan kreativitas, dan keterampilan dalam mengambil keputusan, serta membuat orang menjadi suka membantu (Goleman, Boyatzis \& McKee, 2007).

Goleman (1998) menjelaskan bahwa kecerdasan emosi menciptakan gairah, kepercayaan diri, keramahan, motivasi, harga diri, dan energi pada individu. Kemampuan untuk mengirimkan emosi-emosi yang sama kepada orang lain memberikan keuntungan kepada orang yang cerdas secara emosi atas orang lain dalam konteks komunikasi interpersonal. Zeidner, Matthews, \& Roberts (2004) mengemukakan bahwa kecerdasan emosi memainkan peran penting dalam membentuk perilaku antarpribadi individu sehingga orang-orang dengan kecerdasan emosi yang lebih tinggi akan berhasil dalam mengkomunikasikan tujuan mereka, ide-ide, dan niat mereka dengan cara yang lebih menarik dan tegas.

Faktor luar individu yang berpengaruh terhadap OCB diantaranya adalah kepuasan komunikasi (Chan \& Lai, 2016), komitmen organisasi yang tinggi dan kepuasan kerja dari karyawan (Darmawati, Hidayati, \& Herlina, 2013; Sumiyarsih W, Mujiasih E, Ariati, 2012). Kepuasan individu ketika berhasil berkomunikasi ini kemudian diartikan sebagai kepuasan komunikasi oleh Thayer (Downs \& Hazen, 1977). Ketika karyawan mengalami kepuasan dalam komunikasi di pekerjaannya, maka kepuasan mereka tersebut akan diungkapkan dengan keterlibatannya dalam extra role behavior yang dalam hal ini merupakan suatu bentuk perilaku OCB (Bolino \& Turnley dalam Chan \& Lai, 2016).

Meskipun penelitan mengenai OCB telah dilakukan, namun penelitian mengenai OCB yang dihubungkan dengan kepuasan komunikasi dan kecerdasan emosi sangat terbatas dan jarang dilakukan. Peneliti sebelumnya menyebutkan bahwa baru ada dua penelitian yang menunjukkan adanya hubungan communication satisfaction dengan OCB (Chan \& Lai, 2016) sedangkan untuk kecerdasan emosi dengan OCB sudah ada beberapa penelitian yang dilakukan sebelumnya. Peneliti belum menemukan adanya penelitian yang mengaitkan kecerdasan emosi dan kepuasan komunikasi terhadap OCB padahal kedua aspek tersebut merupakan faktor yang dapat memengaruhi OCB.

Karakteristik bangsa Indonesia adalah menjunjung tinggi nilai kebersamaan dan tolong menolong (Wardani \& Suseno, 2012), penelitian yang dilakukan Fitriastuti (2013) menyebutkan bahwa kecerdasan emosi yang tinggi dibutuhkan untuk berinteraksi dan membina hubungan sosial begitupun dengan kepuasan komunikasi yang akan mendorong seseorang untuk melakukan perilaku ekstra diluar tugasnya sehingga kedua aspek tersebut akan turut mendorong terciptanya perilaku OCB. 


\section{METODE}

Penelitian ini menggunakan metode korelasional. Partisipan dalam penelitian ini adalah 300 karyawan salah satu BUMN di Bandung. pengambilan sampel penelitian ini menggunakan teknik non probabilitas yaitu dengan teknik penyampelan kuota. Pengumpulan data dilakukan dengan menggunakan instrumen kecerdasan emosi berdasarkan teori Goleman yang disusun oleh Muta'asifah (2013), kepuasan komunikasi (Downs dan Hazen, 1977), dan organizational citizenship behavior (OCB) (Kumar dan Shah, 2015). Regresi ganda digunakan sebagai analisis data dalam penelitian ini.

\section{HASIL}

Koefisien korelasi antara kecerdasan emosi dengan organizational citizenship behavior (OCB) adalah sebesar 0,206 (p-0,000), yang artinya terdapat hubungan signifikan antara kecerdasan emosi dan OCB dengan tingkat korelasi yang rendah. Hasil analisis regresi berganda mengenai pengaruh kecerdasan emosi dan kepuasan komunikasi terhadap OCB menunjukkan bahwa koefisien korelasi antara kecerdasan emosi dan kepuasan komunikasi dengan organizational citizenship behavior (OCB) sebesar 0,466 dengan signifikansi $0,000(<0,05)$ sehingga $\mathrm{H}_{0}$ ditolak. Hal ini berarti terdapat pengaruh yang signifikan antara kecerdasan emosi dan kepuasan komunikasi terhadap OCB. Hasil R-square sebesar 0,217 atau sebesar 21,7\% dapat diartikan bahwa kecerdasan emosi dan kepuasan komunikasi berpengaruh terhadap OCB sebesar 21,7\% dan 78,3\% dipengaruhi oleh faktor lainnya yang tidak diteliti dalam penelitian ini.

Hasil penelitian ini memaparkan bahwa karyawan BUMN memiliki tingkat empati sebesar $38 \%$ atau berada pada kategori sedang. Untuk dimensi altruism pada OCB tingkat persentase karyawan BUMN yaitu sebesar $48 \%$ berada pada kategori sedang sehingga hal ini cukup membuktikan penelitian sebelumnya yang menyebutkan bahwa aspek empati pada kecerdasan emosi mempengaruhi aspek altruism pada OCB.

Koefisien korelasi antara kepuasan komunikasi dengan organizational citizenship behavior (OCB) adalah sebesar 0,393 (p-0,000). Hasil penelitian ini menyebutkan bahwa OCB karyawan BUMN di Kota Bandung cenderung dipengaruhi oleh kepuasan komunikasi sebesar 0,393 yang berarti pengaruh kepuasan komunikasi cukup tinggi terhadap OCB. Dalam penelitian ini dapat dikatakan adanya keterkaitan yang signifikan antara kecerdasan emosi, kepuasan komunikasi, dan organizational citizenship behavior 
karena kecerdasan emosi dan kepuasan komunikasi berpengaruh secara bersama-sama terhadap OCB $(\mathrm{p}-0,000<0,05)$.

\section{PEMBAHASAN}

Sekalipun rendah korelasi antara kecerdasan emosi dan OCB, namun penelitian ini sesuai dengan penelitian Kusumajati (2014) yang menemukan bahwa bahwa suasana hati mempengaruhi OCB. Pengaruh kecerdasan emosi terhadap OCB menaikkan variasi OCB sehingga dapat dikatakan semakin tinggi kecerdasan emosi yang dimiliki karyawan, semakin tinggi pula tigkat OCB karyawan tersebut. Lebih spesifiknya, terdapat beberapa penelitian yang membuktikan bahwa kecerdasan emosi memiliki pengaruh positif terhadap OCB. Purba dan Seniati menemukan bahwa individu yang memiliki kestabilan emosi mampu mentolerir ketidaknyamanan dan tidak mengeluh terhadap kesalahan-kesalahan kecil pihak manajemen yang terjadi di tempat kerja (Sumiyarsih W, Mujiasih E, Ariati, 2012).

Aspek kecerdasan emosi yang berpengaruh terhadap OCB adalah aspek empati. Empati akan menjadikan individu termotivasi untuk membantu rekannya (altruism). Adanya empati memungkinkan seseorang dapat memotivasi orang lain sehingga dapat bekerja melakukan yang terbaik (Sumiyarsih W, Mujiasih E, Ariati, 2012). Berdasarkan pernyataan tersebut, dapat dikatakan jika karyawan memiliki aspek empati yang tinggi maka aspek altruism pada OCB juga akan tinggi.

Hasil analisis penelitian ini sesuai dengan hasil penelitian sebelumnya yang menyebutkan bahwa terdapat pengaruh yang positif kepuasan komunikasi terhadap OCB (Chan \& Lai, 2016). Carrier \& Bourque (2008) juga menyebutkan bahwa kepuasan komunikasi didahului atau disebabkan oleh faktor latihan. Adanya interaksi yang terusmenerus atau latihan dalam berkomunikasi ini akhirnya akan membuat karyawan merasa puas terhadap kegiatan komunikasi yang ada di perusahaan.

Kandlousi (2010) menemukan bahwa dimensi kepuasan komunikasi dalam konteks organisasional seperti perspektif organisasi, iklim komunikasi, dan kualitas media merupakan aspek-aspek yang dapat memprediksi tingkat OCB. Kandousi menambahkan bahwa kepuasan komunikasi juga akan berkontribusi positif terhadap sikap antar karyawan. Hasil penelitian tersebut serupa dengan penelitian Berger dkk. (2009) yang menyebutkan bahwa ketika individu merasa puas dengan pekerjaan mereka melalui komunikasi, mereka menerima kualitas yang lebih tinggi dalam interaksi berkelompok dan cenderung akan mengekspresikannya dengan melakukan OCB.

OCB adalah faktor yang memberikan sumbangan pada hasil kerja organisasi secara keseluruhan (Fitriastuti, 2013). OCB dapat timbul dari berbagai faktor dalam organisasi, di antaranya karena pengaruh faktor dari dalam diri individu dan dari luar diri individu (Sumiyarsih W, Mujiasih E, Ariati, 2012). Faktor dari dalam diri individu yang 
berpengaruh terhadap OCB diantaranya adalah suasana hati (Glomb, Bhave, Miner, \& Wall, 2011), dan kecerdasan emosi (Sahafi, Danaee, Sarlak, \& Haghollah, 2012; Sahafi, Danaee, Sariak \& Haghollahi, 2012). Berdasarkan hasil perhitungan, korelasi antara kecerdasan emosi dengan OCB menunjukkan nilai yang positif, artinya tingginya tingkat kecerdasan emosi seseorang akan membuat OCB seseorang akan menjadi tinggi pula.

Hasil penelitian ini juga menyebutkan adanya faktor lain yang meningkatkan variasi OCB. Faktor lain tersebut adalah kepuasan komunikasi. Menurut Bolino \& Turnley (Chan \& Lai, 2016) ketika karyawan merasakan kepuasan dalam berkomunikasi di tempat kerja, kepuasan mereka akan diekspresikan dengan melakukan perilaku diluar perannya (extra-role behavior).

Hasil penelitian tiga variabel (kecerdasan emosi, kepuasan komunikasi, dan organizational citizenship behavior) berada pada kategori sedang. Dua variabel bebas secara terpisah juga menunjukkan adanya pengaruh yang linear yaitu pengaruh kecerdasan emosi menaikkan variasi OCB, begitupun dengan kepuasan komunikasi juga dapat meningkatkan variasi OCB. Dengan demikian, kecerdasan emosi dan kepuasan komunikasi menjadi faktor yang menjelaskan kecenderungan organizational citizenship behavior (OCB) karyawan BUMN di Kota Bandung.

Berdasarkan hasil penelitian, aspek kesadaran diri karyawan merupakan aspek terendah dari kecerdasan emosi sehingga perusahaan harus dapat meningkatkan kesadaran diri karyawan. Hal ini dapat dilakukan dengan pelatihan diantaranya adalah pelatihan konsentrasi dan kepercayaan diri. Salah satu ciri orang dengan kesadaran diri tinggi yaitu memiliki kepercayaan diri yang kuat sehingga pelatihan kepercayaan diri diharapkan dapat meningkatkan kesadaran diri yang dimiliki karyawan. Seseorang dapat merasakan dan mengenali perasaannya ketika ia bisa fokus dan berkonsentrasi terhadap keadaan yang dialaminya sehingga pelatihan konsentrasi diharapkan dapat meningkatkan kesadaran diri karyawan.

Aspek perspektif organisasi dalam variabel kepuasan komunikasi adalah aspek yang memiliki tingkat terendah, yaitu kepuasan mengenai ketersediaan informasi perusahaan secara keseluruhan. Hasil ini membawa implikasi bahwa perusahaan harus dapat memperbaiki sistem penyebaran informasi kepada karyawannya dengan baik yaitu dengan memperhatikan media penyebarannya dan konten informasi yang diberikan kepada karyawan.

Hasil penelitian ini menunjukkan bahwa aspek civic virtue pada organizational citizenship behavior merupakan aspek yang memiliki nilai terendah. Dengan demikian, perusahaan perlu untuk memberikan kesempatan kepada karyawannya untuk terlibat secara langsung dalam kegiatan. 


\section{DAFTAR PUSTAKA}

Chan, S. H. J., \& Lai, H. Y. I. (2016). Understanding the link between communication satisfaction, perceived justice and organizational citizenship behavior. Journal of Business Research. https://doi.org/10.1016/j.jbusres.2016.08.017

Chin, S. T. S., Anantharaman, R., \& Tong, D. Y. K. (2009). Emotional Intelligence and Organisational Citizenship Behaviour of Manufacturing Sector Employees: An Analysis, 6(2), 107-125.

Downs, C. W., \& Hazen, M. D. (1977). A Factor Analytic Study of Communication Satisfaction. Journal of Business Communication, 14(3), 63-73. https://doi.org/ 10.1177/002194367701400306

Fitriastuti, T. (2013). Pengaruh Kecerdasan Emosional, Komitmen Organisasional dan Organizational Citizenship Behavior terhadap Kinerja Karyawan. Jurnal Dinamika Manajemen, 4(2), 103-114.

Glomb, T. M., Bhave, D. P., Miner, A. G., \& Wall, M. (2011). Doing good, feeling good: Examining the role of organizational citizenship behaviors in changing mood. Personnel Psychology, 64(1), 191-223. https://doi.org/http://dx.doi.org/10.1111/j. 1744-6570.2010.01206.x

Karmandita, I. G. N., \& Subudi, M. (2014). Pengaruh Kompetensi Dan Kecerdasan Emosional Terhadap Kinerja Karyawan Di Si Doi Hotel Dan Restaurant Legian. EJournal Management Universitas Udayana, 3(4), 1171-1181.

Kurniawan, A. (2015). Pengaruh Komitmen Organisasi Terhadap Organizational Citizenship Behavior ( Ocb ). Jurnal Manajemen, 15(1), 95-118.

Masruroh, D. (2014). Peranan Kecerdasan Emosi, Kepuasan Kerja dan Kepemimpinan Tranformasional Terhadap Organizational.

Miao, R.-T. (2011). Perceived Organizational Support, Job Satisfaction, Task Performance and Organizational Citizenship Behavior in China, (2004), 105-127.

Natalia, T., \& Suyasa, P.T.Y.S. (2008). Komitmen Organisasi dan Organizational Citizenship Behavior pada Karyawan Call Centre di PT . X, 10(2), 154-169.

Ongkorahardjo, M. D. P. A., Susanto, A., \& Rachmawati, D. (2009). Analisis Pengaruh Human Capital Terhadap Kinerja Perusahaan (Studi Empiris pada Kantor Akuntan Publik di Indonesia). Jurnal Akuntansi Dan Keuangan, 10, PP. 11-21. https://doi.org/10.9744/jak.10.1.PP. 11-21 
Podsakoff, M., Mackenzie, S. B., \& Moorman, H. (1990). Leader Behaviors and Their Effects on Followers' Trust in Leader, Satisfaction, and Citizenship Behaviors, (2), $107-142$.

Sahafi, E., Danaee, H., Sarlak, M. A., \& Haghollah, F. (2012). The Impact of Sympathetic Components of Emotional Intelligence on Citizenship Behavior of Physicians. Journal of Family \& Reproductive Health, 6(1), 5-9. Retrieved from http://search. ebscohost.com/login. aspx $?$ direct $=$ true $\& \mathrm{db}=\mathrm{a} 9 \mathrm{~h} \& \mathrm{AN}=76281663 \&$ site=ehost-live

Sumiyarsih W, Mujiasih E, Ariati, J. (2012). Hubungan antara kecerdasan emosional dengan organizational citizenship behavior (OCB) pada karyawan CV. Aneka Ilmu Semarang. Jurnal Psikologi Undip, 11(1). 